\title{
Cross Circulated Management for Cross-Cloud in Multi Cloud Environment
}

\author{
S. Theivasigamani, D. Jeyapriya, C. Anuradha
}

\begin{abstract}
Cloud figuring is a dispersed registration hubs arrangement. The appropriation of virtual machine (VM) images in a Cross-Cloud finding situation to an agreement of transmitted system hubs is a major problem discussed in this article. This paper will manage the issue of planning virtual machine (VM) images in a Cross-Cloud registration condition to arrange appropriate process hubs. To tackle this problem, this paper proposes and updates a productive strategy for VM administration. The outcome will be utilized as a compelling planning direction for VM booking on distributed computing and cross distributed computing condition.
\end{abstract}

Keywords: virtual machine (VM) picture; cross-distributed computing; planning.

\section{INTRODUCTION}

Due to its component of asset sharing and offering customers a practical elevated computing velocity, conveyed processing has achieved elevated growth. Distributed computing and virtualization are two of the decade's important IT models. There are such a large number of territories of suggestions gave by distributed computing which incorporates, upgraded information calculation, financially savvy, decrement in operational assets, streamlined asset arrangement, improved programming advancement, versatility in information get to, security, and so forth. Consequently to give savvy calculations, cloud condition should be worked in a proficient way[1-6].

It was conceivable to display registry assets as Virtual Machine (VM) Images after virtualization. In distributed computing, virtualization implies a distinctive role. Regularly VMs are provided in different kinds, each type has its own characteristics that includes amount of CPU facilities, memory measurement, and so on, and price. To fulfill the requirements of such a superior calculations develops the utilization of united mists and multi-cloud organizations. A Cross-Cloud figuring condition is the communication of at least two Cloud processing destinations offering diverse calculations. On the off chance that the Cloud worldview is to be stretched out to encourage cross supplier use of assets, a few difficulties should be unraveled. The organization instrument ought to have the capacity to adapt to both bunch situations and more heterogeneous, dispersed Cross-Cloud figuring conditions, which additionally incorporates desktop frameworks as found in private Clouds. This document is

Revised Manuscript Received on August 22, 2019.

S. Theivasigamani Department of CSE, Bharath Institute of Higher Education and Research, Chennai, Tamilnadu, India.

D. Jeyapriya, Department of CSE, Bharath Institute of Higher Education and Research, Chennai, Tamilnadu, India.

C. Anuradha, Department of CSE, Bharath Institute of Higher Education and Research, Chennai, Tamilnadu, India. written as follows. Initially, the self-reservation calculation written poll is provided in section 2. At that stage, fresh suggested FSS extension is being discussed, HFSS expounded in area 3 and also suggested framework layout. At that point segment 4 closes the paper giving thought without bounds work [7-11].

\section{EXISTING SCHEDULING SCHEMES}

This segment portrays distinctive planning calculations best appropriate for the circulated and profoundly heterogeneous condition for VM picture booking.

\section{A. Circle Scheduling Schemes}

In static despite the reservation ring emphasis, room is equitably divided into $\mathrm{n}$ parts and each of these lumps is subsequently doled out to a processor. It is called dynamic planning at the stage where a piece of circle emphasis is delivered at runtime by a stand still processor. [6-10]. Guided planning is to some degree like dynamic booking, however piece estimate continue contracting per dispatch. Cross-Cloud figuring stage is disseminated, powerfully changing and amazingly heterogeneous, which may contain mists, billow of mists, and so forth. Considering necessities of such a domain circle booking plans are is by all accounts reasonable for compelling planning. Essentially circle booking plans are arranged by the time at which planning choice is made [12-14].

\section{B. Scheduling Schemes}

Proficient booking on dispersed frameworks, for example, heterogeneous bunch and matrix processing is for the most part influenced by stack adjusting. This area introduces a general approach toward various self planning plans. A few best performing self booking plans are assessed here as underneath:

Self-Scheduling (SS): is depicted through the reservation process. It can gradually alter the number of cycles per processor. In this piece estimate is powerfully computed as It in some cases offer great load adjust with little planning overhead, by allotting extensive size pieces toward the start of a parallel circle. Factorizing Self-Scheduling (FSS): Assignments are planned for clumps of $\mathrm{P}$ pieces of equivalent size as Just a subset of the rest of the assignments is planned for each bunch. FSS offers better load adjust when contrasted with the GSS when execution time changes broadly and arbitrarily [15-18]. 


\section{RELATED WORK}

\section{A. Heterogeneous Factorizing Self-Scheduling Scheme}

HFSS is suggested here in perspective of the written audit outlined in the previous table of the current FSS. HFSS draws on a number of previous reservation system ideas and characteristics to best suit the highly heterogeneous and topographically spread Cross-Cloud situation. It is said to be heterogeneous as it would give to factorize self-booking. Better load adjustment when extensive and arbitrary shifts in execution moment. Dynamic choice for implementation execution. Parceling of circle cycles as per the present execution Trapezoid Self-Scheduling (TSS): It keeps up sensible load adjust while endeavoring to diminish the requirement for synchronization [9]. It directly diminishes the piece measure. Substantial lumps of cycles are allotted to the initial couple of processors and progressively littler pieces to the last couple of processors. In [19] the author suggested fresh improved schemes for self-planning called NGSS and ANGSS. In relation to the self-planning scheme, NGSS was originally obtained from GSS. A self-booking isolates the workload in two allotments; their execution will dispatch the first percent of the workload while remaining (100-) percent of the workload dispatched by a highly characterized self-planning plan. Next, the plan is upgraded from GSS to ANGSS, characterizing the kind of circle emphasis in four classes. The creator has indicated execution of these booking plans with the end goal of assessment. [20-24]As per the outcomes acquired by the creator says that conventional self booking plans. From this exchange FSS plot is chosen for execution with some new advancements added to accomplish proficiency in to a great degree heterogeneous condition. This moved forward The changed and proposed calculation is as beneath:

At Scheduler:

Acknowledge VM request from the client at scheduler. Scheduler will recognize the percentage of the heap of the related servers to one (the least stacked) processing hub.At Compute Node:

The register hub allocated to the assignment will track its execution time. Finally, the time required for each errand will be calculated and the result will be evaluated.

This distribution provides better load adjustment and helps with cloud execution. The following subsection of the framework design clarifies the work illustration [25].

\section{RESULTS AND DISCUSSION}

The scheduler is performed as shown in Figure 1. The scheduling calculation indicated above will be executed by the L-Scheduler for multi-cloud situation. Cloud Server-1: It's going to be a Student Management Server.

In show situation, overseeing understudies in instructive foundation is a greater test. This will give an answer for the everyday regulatory operations and to do instructive foundation works cleverly.

Cloud Server-2: It will give office to Finance Management.

-First it goes to the separate serve asked for calculation.

- Once the demand achieves the coveted server, at that point the customer server gets associated and calculations are completed. This process goes on consistently for all the approaching solicitations. This work process is taken after easily with the shared figuring system. This system gives high adaptability, as it is conceivable to add more companions to the framework and can scaled to bigger system .Along these lines it is useful for huge scale calculations [26,27].

Cloud Server-3: Matrix Multiplication.

Extensive grid increase will be conducted on this server. This will be performed to verify the reaction time and computing velocity for multiple expansive grid increases. On each cloud server, these administrations will be described which offer earlier stated usefulness on the individual cloud server At whatever stage a request comes from a client, it will first be recognized on the correct cloud server. At this neighboring cloud location, the scheduler will serve the approaching solicitation to better suit that cloud server's prerequisite. In the associated developments, this is clarified: $\bullet$ The request stems from a client.

First, it comes to the calculation requested by the person serve.

-If our cloud is demanded, it is reserved to the finest computer centre.(genuine figure hubs) with the assistance of proposed calculation

-Once the demand achieves the coveted server, at that point the customer server gets associated and calculations are completed.

-This process goes on persistently for all the approaching solicitations.

This work process is taken after easily with the distributed figuring system. This scheme provides a large degree of versatility as it is conceivable to add more partners to the structure and can be scaled to a larger system[28-30]. It is helpful for large-scale calculations in this manner. On one understudy administration cloud server, the two servers will have two distinctive understudy databases. The approaching request will be allocated and handled on the servers keeping the necessary database. Demand will be allocated along these lines and feasible load adjustment will be achieved under heterogeneous conditions. Such real apps will evaluate the framework at each cloud server.

\section{CONCLUSION}

In this paper a current circle booking calculations are exhibited. A heterogeneous factorizing self-scheduling calculation for use in virtual machine scheduling for cross-cloud situation is suggested and regarded from previous inquiry. Such an execution is not yet completed with the suggested cross-cloud phase. Framework development is suggested to anticipate each cloud server with point-by-point execution. The research is in progress, therefore document will integrate the complete after-effect of the suggested calculation showing feasible VM scheduling. This job will offer the cross-cloud VM scheduling a smart idea. 


\section{REFERENCES}

1. Gowri Sankaran, B., Karthik, B. \& Vijayaragavan, S.P. 2019, "Weight ward change region plummeting change for square based image huffman coding", International Journal of Innovative Technology and Exploring Engineering, vol. 8, no. 10, pp. 4313-4316.

2. Gowri Sankaran, B., Karthik, B. \& Vijayaragavan, S.P. 2019, "Image compression utilizing wavelet transform", International Journal of Innovative Technology and Exploring Engineering, vol. 8, no. 10, pp. 4305-4308.

3. Kandavel, N. \& Kumaravel, A. 2019, "Offloading computation for efficient energy in mobile cloud computing", International Journal of Innovative Technology and Exploring Engineering, vol. 8, no. 10, pp. 4317-4320.

4. Vinoth, V.V. \& Kanniga, E. 2019, "Reversible data hiding in encrypting images-an system", International Journal of Engineering and Advanced Technology, vol. 8, no. 6, pp. 3051-3053.

5. Selvapriya, B. \& Raghu, B. 2019, "Pseudocoloring of medical images: A research", International Journal of Engineering and Advanced Technology, vol. 8, no. 6, pp. 3712-3716.

6. Senthil Kumar, K. \& Muthukumaravel, A. 2019, "Bi-objective constraint and hybrid optimizer for the test case prioritization", International Journal of Engineering and Advanced Technology, vol. 8, no. 6 , pp. 3436-3448.

7. Kavitha, G., Priya, N., Anuradha, C. \& Pothumani, S. 2019, "Read-write, peer-to-peer algorithms for the location-identity split", International Journal of Innovative Technology and Exploring Engineering, vol. 8, no. 9 Special Issue 3, pp. 445-447.

8. Kaliyamurthie, K.P., Michael, G., Anuratha, C. \& Sundaraj, B. 2019 "Certain improvements in alzheimer disease classification using novel fuzzy c means clustering for image segmentation", International Journal of Innovative Technology and Exploring Engineering, vol. 8, no. 9 Special Issue 3, pp. 599-604.

9. Kaliyamurthie, K.P., Sundarraj, B., Geo, A.V.A. \& Michael, G. 2019, "RIB: Analysis of I/O automata", International Journal of Innovative Technology and Exploring Engineering, vol. 8, no. 9 Special Issue 3, pp. 1019-1022.

10. Velvizhi, R., Rajabhushanam, C. \& Vidhya, S.R.S. 2019, "Opinion mining for travel route recommendation using Social Media Networks (Twitter)", International Journal of Innovative Technology and Exploring Engineering, vol. 8, no. 9 Special Issue 3, pp. 508-512.

11. Kavitha, R., Sangeetha, S. \& Varghese, A.G. 2019, "Human activity patterns in big data for healthcare applications", International Journal of Innovative Technology and Exploring Engineering, vol. 8, no. 9 Special Issue 3, pp. 1101-1103.

12. Pothumani, S., Anandam, A.K., Sharma, N. \& Franklin, S. 2019, "Extended VEOT framework - Implemented in a smart boutique", International Journal of Innovative Technology and Exploring Engineering, vol. 8, no. 9 Special Issue 3, pp. 762-767.

13. Kaliyamurthie, K.P., Michael, G., Krishnan, R.M.V. \& Sundarraj, B. 2019, "Pseudorandom techniques for the internet", International Journal of Innovative Technology and Exploring Engineering, vol. 8, no. 9 Special Issue 3, pp. 915-918

14. Aravindasamy, R., Jeffrin Rajan, M., Rama, A. \& Kavitha, P. 2019, "Deep learning provisions in the matlab: Focus on CNN facility", International Journal of Innovative Technology and Exploring Engineering, vol. 8, no. 9 Special Issue 3, pp. 990-994.

15. Theivasigamani, S., Linda, M. \& Amudha, S. 2019, "Object sensing and its identification \& motion sensing", International Journal of Innovative Technology and Exploring Engineering, vol. 8, no. 9 Special Issue 3, pp. 545-549.

16. Mary Linda, I., Vimala, D. \& Shanmuga Priya, K. 2019, "A methodology for the emulation of IPv4", International Journal of Innovative Technology and Exploring Engineering, vol. 8, no. 9 Special Issue 3, pp. 848-852.

17. Velvizhi, R., Priya, D.J., Vimala, D. \& Linda, I.M. 2019, "Increased routing algorithm for mobile adhoc networks", International Journal of Innovative Technology and Exploring Engineering, vol. 8, no. 9 Special Issue 3, pp. 1606-1608.

18. Sangeetha, S., Anuradha, C. \& Priya, N. 2019, "DNS in real world", International Journal of Innovative Technology and Exploring Engineering, vol. 8, no. 9 Special Issue 3, pp. 937-940.

19. Geetha, C., Vimala, D. \& Priya, K.S. 2019, "Constructing multi-processors and spreadsheets with SKIVE", International Journal of Innovative Technology and Exploring Engineering, vol. 8, no. 9 Special Issue 3, pp. 516-519.

20. Yugendhar, K., Sugumar, V. \& Kavitha, P. 2019, "A novel method of univac using fuzzy logic", International Journal of Innovative
Technology and Exploring Engineering, vol. 8, no. 9 Special Issue 3, pp. 435-437.

21. Kaliyamurthie, K.P., Michael, G., Elankavi, R. \& Jijo, S.A. 2019 "Implementing aggregate-key for sharing data in cloud environment using cryptographic encryption", International Journal of Innovative Technology and Exploring Engineering, vol. 8, no. 9 Special Issue 3, pp. 957-959.

22. Jeffrin Rajan, M., Aravindasamy, R., Kavitha, P. \& Rama, A. 2019, "A novel method of object orientation variation in $\mathrm{C}++$ and java", International Journal of Innovative Technology and Exploring Engineering, vol. 8, no. 9 Special Issue 3, pp. 708-710.

23. Nayak, R., Dinesh, S. \& Thirunavukkarasu, S. 2019, "A novel method improvement of rapid miner for the data mining applications", International Journal of Innovative Technology and Exploring Engineering, vol. 8, no. 9 Special Issue 3, pp. 457-460.

24. Sivaraman, K., Krishnan, R.M.V., Sundarraj, B. \& Sri Gowthem, S. 2019, "Network failure detection and diagnosis by analyzing syslog and SNS data: Applying big data analysis to network operations", International Journal of Innovative Technology and Exploring Engineering, vol. 8, no. 9 Special Issue 3, pp. 883-887.

25. Vimala, D., Linda, I.M. \& Priya, K.S. 2019, "Decoupling online algorithms from erasure coding in DNS", International Journal of Innovative Technology and Exploring Engineering, vol. 8, no. 9 Special Issue 3, pp. 950-953.

26. Rama, A., Kumaravel, A. \& Nalini, C. 2019, "Preprocessing medical images for classification using deep learning techniques", International Journal of Innovative Technology and Exploring Engineering, vol. 8, no. 9 Special Issue 3, pp. 711-716.

27. Sangeetha, S., Srividhya, S.R., Anita Davamani, K. \& Amudha, S. 2019 "A procedure for avoid overrun error in universal synchronous asynchronous receiver transmitter (usart) by utilizing dummy join and interrupt latency method", International Journal of Innovative Technology and Exploring Engineering, vol. 8, no. 9 Special Issue 3, pp. 657-660.

28. Aravindasamy, R., Jeyapriya, D., Sundarajan, B. \& Sangeetha, S. 2019 "Data duplication in cloud for optimal performance and security", International Journal of Innovative Technology and Exploring Engineering, vol. 8, no. 9 Special Issue 3, pp. 1156-1158.

29. Aravindasamy, R., Jeffrin Rajan, M., Sugumar, V. \& Kavitha, P. 2019, "A novel method on developing superblocks and the transistor using apodryal", International Journal of Innovative Technology and Exploring Engineering, vol. 8, no. 9 Special Issue 3, pp. 982-985.

30. Sasikumar, C.S. \& Kumaravel, A. 2019, "E-learning attributes selection through rough set theory and data mining", International Journal of Innovative Technology and Exploring Engineering, vol. 8, no. 10, pp. 3920-3924

\section{AUTHORS PROFILE}

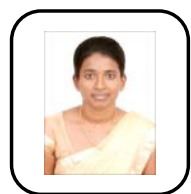

S. Theivasigamani, Assistant Professor, Department of Computer Science \& Engineering, Bharath Institute of Higher Education and Research, Chennai, India

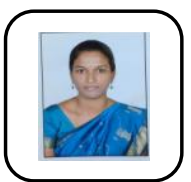

D. Jeyapriya, Assistant Professor, Department of Computer Science \& Engineering, Bharath Institute of Higher Education and Research, Chennai, India

C. Anuradha, Assistant Professor, Department of Computer Science \& Engineering, Bharath Institute of Higher Education and Research, Chennai, India 